\title{
VERDADE, INTERPRETAÇÃO E OBJETIVIDADE EM DONALD DAVIDSON*
}

\begin{abstract}
José Maria Arruda**
SÍNTESE - Donald Davidson foi um dos filósofos mais influentes da tradição analítica da segunda metade do século. A unidade de sua obra é constituída pelo papel central que reflexão sobre como podemos interpretar os proferimentos de um outro falante desempenha para a compreensão da natureza do significado. Davidson adota o ponto de vista metodológico de um intérprete que não pode pressupor nada sobre o significado das palavras de um falante e que não possui nenhum conhecimento detalhado de suas atitudes proposicionais. Neste artigo, eu apresento inicialmente a estrutura e os pressupostos da filosofia da linguagem de Davidson; passo depois a uma discussão sobre a importância do princípio de caridade para seu projeto interpretativo e, por fim, procuro apontar as diferenças do projeto de Davidson com a hermenêutica filosófica.

PALAVRAS-CHAVE - Interpretação radical Princípio de caridade. Hermenêutica.

ABSTRACT - Donald Davidson was one of the most influential philosophers in the analytic tradition in the last half of the twenthy century. The unity of his work lies in the central role that the reflection on how we are able to interpret the speech of another plays in undestanding the nature of meaning. Davidson adopts the standpoint of the interpreter of the speech of another whose evidence does not, at the outset, pressupose anything about what the speaker's words mean or any datailed knowledge of his propositional attitudes. This is the position of the radical interpreter. In this paper, I begin with an account of the assumptions and structure of Davidson's philosophy of language; after this I discuss the philosophical importance of the principle of charity for the theory of radical interpretation and, at the end, I compare Davidson's interpretative project to the philosophical hermeneutic.

KEY WORDS - Radical interpretation. Principle of charity. Hermeneutics.
\end{abstract}

A filosofia da linguagem tem se dividido comumente em duas províncias distintas: a filosofia analítica e a hermenêutica filosófica. Salvo raras exceções, em regra, aqueles que se ocupam da análise lógica da linguagem manifestam pouco

* Este artigo foi produzido no âmbito de uma pesquisa sobre o Idealismo Alemão e a Filosofia PósAnalítica Contemporânea que realizei no inverno 2003/2004 no Instituto de Filosofia da RWTH Aachen/Alemanha, com bolsa concedida pelo DAAD/CAPES. Ao Prof. Dr. Dieter Wandschneider e ao Prof. Dr. Wolfgang Kuhlmann agradeço pela acolhida calorosa e pelas estimulantes discussões. Meu colega, Prof. Dr. Manfredo Araújo de Oliveira, leu uma versão preliminar do texto e fez sugestões preciosas.

** Doutor. Professor do Departamento de Filosofia e do Programa de Pós-Graduação em Filosofia da UFC (Universidade Federal do Ceará).

\begin{tabular}{|l|l|l|l|l|l|}
\hline VERITAS & Porto Alegre & v. 50 & n. 1 & Março 2005 & p. 137-154 \\
\hline
\end{tabular}


interesse pelas questões desenvolvidas pelos hermeneutas, e vice-versa. Dessa forma, filosofia analítica e hermenêutica têm se constituído como modelos de "racionalidade" distintos, e mesmo excludentes. Mas estão realmente a filosofia analítica e a hermenêutica situadas em mundos paralelos intangíveis? Ou é possível encontrar motivos comuns que permitam estabelecer um diálogo produtivo entre essas duas grandes províncias da filosofia contemporânea?

Donald Davidson foi um dos raros filósofos contemporâneos que ajudaram a construir uma ponte entre a filosofia analítica e a hermenêutica. Sua obra inovadora, precisa, elegante e, muitas vezes, hermética é um dos marcos da filosofia analítica pós-positivista. Com a crítica ao dualismo "esquema conceitual/conteúdo" - o terceiro dogma do empirismo, ele superou o último resquício empirista da filosofia de Quine e, juntamente com Willfrid Sellars, deu um novo impulso para a filosofia americana recente, influenciando fortemente autores como Richard Rorty, John McDowell e Robert Brandom. Em sua maior parte, a obra de Davidson gira em torno de questões semântico-lingüísticas, da relação mente-corpo e da teoria da ação. Davidson não foi um autor de livros; fiel à tradição analítica, ele sempre preferiu os pequenos artigos, publicados sobretudo em revistas especializadas e anais de congressos. Sua primeira coletânea de artigos, Essays on Action and Events, somente apareceu em 1980 e reunia textos sobre a filosofia da mente e da ação; em 1984, o segundo livro, Inquiries into Truth and Interpretation, reuniu seus artigos sobre a filosofia da linguagem. O fato de sua produção ter se dado predominantemente na forma de artigos foi certamente a razão de ele ter sido descoberto tardiamente e de não se ter percebido mais cedo o caráter sistemático de seu pensamento. MacIntyre referiu-se a ele, certa vez, como "o Plotino de nossa época".

A primeira fase dos escritos de Davidson tem como centro três tópicos programáticos básicos: (a) a defesa da possibilidade de construção de teorias de verdade finitamente axiomatizáveis para linguagens naturais que incluíam em suas conseqüências lógicas sentenças-T que forneciam as condições de verdade para cada sentença da linguagem investigada; (b) tal teoria deveria servir como teoria semântica; e (c) seria possível verificar empiricamente a correção de tal teoria semântica para um grupo definido de falantes através da comparação das condições em que os falantes tomam suas sentenças por verdadeiras e as condições de verdade assinaladas pela teoria para aquelas sentenças. Na seqüência, o conceito de "interpretação radical" e, posteriormente, a idéia da "triangulação" assumem cada vez mais uma posição central. A análise semântica, em que questões teórico-formais aparecem em primeiro plano, é deslocada em direção a uma teoria interpretativa dos proferimentos dos falantes, em que é vedado ao intérprete qualquer acesso privilegiado às intenções e ao significado do falante. Para Davidson, as crenças, desejos, atitudes e proferimentos de uma pessoa formam uma unidade holística, por isso a compreensão do significado de expressões lingüísticas só é possível a partir de uma teoria da verdade e da interpretação que lance mão de alguns pressupostos sobre a racionalidade humana e a sociabilidade. Após expor a 
função da interpretação na filosofia de Davidson, pretendo apontar suas diferenças com a hermenêutica filosófica.

\section{Teoria da verdade e semântica formal}

Para Davidson, a filosofia da linguagem tem por objetivo principal a compreensão de linguagens naturais, que são a base de toda e qualquer compreensão lingüística. Por linguagem natural, ele entende um conjunto de signos que tiveram ou têm uso efetivo atual. Sistemas formais não-interpretados não podem ser considerados linguagens propriamente, pois suas expressões carecem de significado, e sistemas formais interpretados podem ser vistos como extensões ou fragmentos da linguagem natural ([1], 71). Uma teoria da linguagem não deve pretender reformar ou substituir as linguagens naturais, mas limitar-se a descrever seu funcionamento e entender os proferimentos dos falantes ([1], 29). A tarefa de uma teoria da semântica de uma linguagem L qualquer é dar o significado de toda expressão significativa de L.

Para Davidson, uma teoria semântica de uma linguagem L somente pode se constituir enquanto teoria composicional de L, fornecendo o significado das sentenças de L complexa em função do significado de seus constituintes semanticamente menos complexos e de seus modos de combinação. Em outras palavras: a teoria tem que ser necessariamente recursiva e mostrar que todo o potencial expressivo de uma linguagem pode ser axiomatizado e analisado a partir de um procedimento operacional finito ([1], 55), consistindo em vocabulário finito e um número finito de regras de aplicação. A teoria deve, portanto, preservar um traço distintivo das linguagens: o seu caráter holístico-composicional. Cada palavra só tem sentido no contexto de uma sentença e cada sentença, por sua vez, só tem sentido no contexto da linguagem como um todo, pois o significado de uma sentença só se deixa determinar pela determinação do significado de todas as outras sentenças ([1], 22). Além disso, nenhuma teoria semântica pode ser considerada adequada se ela não fornecer uma abordagem do conceito de verdade para a linguagem a ser compreendida ([1], 55). Por teoria da verdade deve-se entender um conjunto de axiomas que contém, para cada sentença s de L, uma enunciação das condições sob as quais s é verdadeira em L. Procedendo assim, seria em princípio perfeitamente possível dar um tratamento formal a linguagens naturais.

A teoria semântica tradicional tinha como ideal construir sentenças do tipo "s significa p", para toda sentença s de L. Aceitando, porém, as críticas de Quine à noção de significado como entidade abstrata, parece que tal ideal é ilusório. Para evitar o apelo à obscura noção de significado, Davidson vai propor a aplicação da convenção-T de Tarski e substituir a sentença "s significa p" por sentenças-T do tipo "s é verdadeira se e somente se p". Ao invés de associar o significado de s ao significado de $\mathrm{p}$, a teoria associa $\mathrm{s}$ às condições de verdade descritas em p. Essa estratégia pretende evitar as aporias da teoria do significado tradicional e construir uma teoria de compreensão das expressões lingüísticas de L à luz de uma teoria da verdade de L ([1], 23). O significado de uma sentença s em uma linguagem L é 
fixado através de um teorema de verdade da forma "s é verdadeira se e somente se p". Com a idéia da centralidade do conceito de verdade para uma teoria do significado, Davidson crê ser fiel a uma das teses básicas da semântica de Frege e Wittgenstein: conhecer o significado de uma sentença é conhecer as condições sob as quais essa sentença é verdadeira. Para ele, as condições de verdade de s, descritas em p, são uma forma de indicação do significado de s. Se identificamos uma teoria do significado com aquilo que devemos conhecer para entender cada sentença de uma linguagem L qualquer, então tal teoria poderia ser formulada através da teoria de verdade que usamos para interpretar L. Uma teoria adequada deve, assim, gerar recursivamente para cada sentença s de L uma sentença-T correspondente, ordenando s e p. Os axiomas de tal teoria, que usa termos sinônimos na sentença $\mathrm{p}$ da meta-linguagem para enunciar as condições de verdade de s em L, podem ser ditos interpretativos de L e a teoria que contém tais axiomas deve ser considerada como uma teoria da verdade interpretativa de L.

Segundo Davidson, a teoria da verdade de Tarski pode satisfazer os critérios de uma teoria do significado para linguagens naturais, desde que, porém, alguns ajustes sejam promovidos. O primeiro deles é reconhecer que o valor de verdade das sentenças varia a) conforme o momento em que são proferidas, b) conforme o falante e c) conforme a audiência. Não se trata mais, portanto, de construir uma teoria da verdade para sentenças, mas sim para proferimentos e atos-de-fala envolvendo o falante e o contexto dos seus proferimentos ([1], 58). Neste sentido, a teoria deve acomodar termos indexadores e expressões demonstrativas. A segunda mudança consiste em não usar mais noções semânticas - como significado, sinonímia e analiticidade - para definir a relação de satisfação entre o lado esquerdo e o lado direito da sentença bicondicional T; a equivalência é resultado da teoria e, portanto, não pode ser pressuposta por ela.

Se tomarmos a função invariante "é verdadeiro se e somente se" como "significa que", fica claro que p daria o significado de s em termos de suas condições de verdade. No caso mais simples, a convenção T é satisfeita pela substituição de s por ela mesma, como no célebre exemplo de Tarski: ""a neve é branca" é verdadeira se e somente se a neve é branca". Como aqui a linguagem-objeto está contida completamente na meta-linguagem, o teste é meramente formal. O problema é quando s e p não são sentenças idênticas. Como estabelecer, neste caso, critérios de satisfação da sentença-T? Como construir bicondicionais cujo lado direito não seja uma mera repetição do lado esquerdo? Segundo Davidson, resolver esse problema é indicar os critérios de satisfação da bicondicional sem apelar para conceitos semânticos.

Um falante de português não teria problemas de identificar a verdade ou falsidade do proferimento "a criança está dormindo", pois ele sabe que esse proferimento é verdadeiro se e somente se a criança está dormindo no momento em que o falante executa seu proferimento. Para não cair no erro da analiticidade ou sinonímia, imaginemos um lingüista de campo que tem que interpretar um proferimento feito em uma linguagem completamente diferente da sua. O lingüista tem que ordenar cada proferimento do falante a uma sentença de sua própria lingua- 
gem. A única forma de fazer isso é associar os proferimentos do falante com condições de verdade tomadas pelo lingüista como válidas no momento do proferimento. Dessa forma, o que ligaria a sentença do lado esquerdo e a sentença do lado direito é que elas têm a mesma extensão. A sentença p somente será uma boa candidata se ela for verdadeira nas mesmas condições em que $\mathrm{s}$ for verdadeira. Para fortalecer a teoria, mais um critério deve ser observado: não basta que o lingüista estabeleça uma correspondência estrita entre alguns s e alguns p; a teoria tem que estabelecer a correspondência entre todas as sentenças s e todas as sentenças p. Uma vez que, para cada sentença de L, existe uma sentença-T correspondente, então só a totalidade das sentenças-T pode fixar o significado de cada uma das expressões lingüísticas de L. Dessa forma, diminui-se a margem de erro da teoria. A teoria somente pode ser testada holisticamente e o lingüista tem que poder testar várias seqüências de sentenças-p buscando satisfazer seqüências de sentenças- $\mathrm{T}$ :

What we have overlooking, however, is that we have supplied an alternative criterion: this criterion is that the totality of T-sentences should... optimally fit evidence about sentences held true by native speakers. The present idea is that what Tarski assumed outright for each T-sentence can be indirectly elicited by a holistic constraint ([1], 139).

Dada as relações de interdependência lógico-semântica entre as sentenças de uma linguagem, nem todas, somente algumas dessas seqüências serão consistentes: "there is no giving the truth conditions of all sentences without showing that some sentences are logical consequences of others" ([1], 61).

O caráter inovador da proposta de Davidson nunca foi posto em dúvida, mas sim a exeqüibilidade de seu projeto. Primeiramente, não é muito claro como uma teoria do significado à base da convenção-T poderia realmente ser testada empiricamente. Segundo, mesmo que se refira a linguagens naturais, Davidson só utiliza sentenças declarativas logicamente bem comportadas. Terceiro, é possível construir formalmente sentenças $\mathrm{T}$ com sentenças $(\mathrm{s}, \mathrm{p})$ obtendo exatamente os mesmos valores de verdade em todas as circunstâncias, sem que daí se derive a equivalência de significados entre as sentenças s e p. Como ressaltou I. Hacking ([1], 140ss) se é correto afirmar que "“a neve é branca" é verdadeira, se e somente se, a neve é branca", também é igualmente correto afirmar que " "a neve é branca" é verdadeira se e somente se a grama é verde"; ou que "“A é um animal com coração" se e somente se A é um animal com rins". Seria tão absurdo dizer que "a neve é branca" significa o mesmo que "a grama é verde" quanto dizer que "ter coração" significa o mesmo que "ter rins". Quarto, como assinalou J. A. Foster (1976), ao que parece, as sentenças-T são formalmente corretas, mas incapazes de fornecer uma interpretação adequada para os termos situados nos extremos da bicondicional. Somente podemos aplicar a convenção-T para linguagens que já conhecemos e dominamos, isto é, para linguagens já devidamente interpretadas. Por fim, como frisou M. Dummet ([1], 101s.), para compreender o significado da expressão do lado esquerdo da convenção-T é necessário já conhecer o significado da expressão do lado direito. Logo, a teoria davidsoniana não seria uma teoria 
plena do significado, e sim uma mera teoria da tradução com pretensões modestas. Para Dummet, uma teoria do significado à base da teoria da verdade de Tarski não diz nada de novo e, no fundo, pressupõe aquilo que deveria explicar.

Essas objeções levaram Davidson a redimensionar seu projeto original e a se dedicar mais detidamente à questão da interpretação de expressões lingüísticas. Sua contribuição original em relação à concepção extensionalista de Tarski vai consistir em defender que, quando a linguagem-objeto não está contida na metalinguagem, a única forma de encontrar suporte empírico para a bicondicional é adscrever aos falantes intenções e atitudes proposicionais racionais semelhantes às do intérprete e supor que as circunstâncias externas comuns a ambos podem fornecer elementos para uma teoria da interpretação de seus proferimentos e de sua linguagem. A semântica formal tem que estar ancorada em uma teoria da interpretação: "Convention T, even when bent to fit the awkard shapes of natural language, points the way to a radical theory of interpretation"([1], 75). A única forma de estabelecer critérios de satisfação da convenção-T é estabelecer critérios para a interpretação entre as sentenças do lado esquerdo e do lado direito da bicondicional. Davidson é levado assim à questão das condições de possibilidade da interpretação lingüística enquanto tal.

\section{A interpretação radical}

A idéia de uma interpretação radical tem afinidades e diferenças com o modelo quineano de uma tradução radical, exposto no capítulo II de Word and Object. O intérprete radical também não pode fazer apelo a significados tomados como entidades abstratas pré-lingüísticas e de valor explicativo nulo ([1] 126). Tampouco pode o intérprete extrair suas evidências com base nas supostas intenções do falante, pois não é possível ter acesso e discernir essas intenções antes de interpretar as sentenças proferidas por ele. Por outro lado, a noção quineana de "stimulus-meaning", como uma espécie de evidência empírica independente para a construção de teorias, é ainda uma forma de empirismo radicado na separação entre esquema conceitual-conteúdo ([8], 49s). Para essa noção, Davidson afirma não encontrar nenhum uso, pois não é possível estabelecer nenhuma distinção clara entre sentenças observacionais e sentenças teóricas. O problema é então o seguinte: como obter uma interpretação bem sucedida se o intérprete não pode se apoiar nem em significados dados, nem em intenções prévias e nem em relações causais unívocas entre estímulos e respostas verbais do falante?

Responder a esta questão significa estabelecer em que condições a interpretação de proferimentos alheios pode ser bem sucedida, supondo que a única evidência disponível para o intérprete é o comportamento verbal do falante e as circunstâncias do mundo no momento em que ele profere suas sentenças: "The semantic features of language are public features. What no one can, in the nature of the case, figure out from the totality of the relevant evidence cannot be part of meaning" ([1], 235). A interpretação radical não pretende ser uma investigação dos processos de aprendizagem lingüística ou teoria psicológica, pois uma teoria satis- 
fatória da interpretação não pode ser confundida com sentenças sobre o conhecimento proposicional do intérprete, nem com sentenças acerca dos mecanismos internos de alguma parte de seu cérebro ([4], 438). Uma interpretação é bem sucedida quando é capaz de dizer o que as palavras do falante significam por ocasião do seu uso ([1], 141). Isso quer dizer que o intérprete deve ser capaz de, a cada proferimento do falante, atribuir uma sentença em sua própria linguagem. As sentenças do intérprete fornecerão as condições de verdade dos proferimentos do falante e, assim, é possível obter uma caracterização recursiva da verdade das sentenças atuais e potenciais do falante, segundo o ponto de vista do intérprete.

Metodologicamente, o intérprete precisa admitir de antemão uma estreita vinculação entre as crenças (belief) do falante - enquanto um estado interno que condensa sua dimensão intensional - e o significado (meaning) de seus proferimentos. Trata-se, fundamentalmente, segundo Davidson, de adscrever atitudes proposicionais ao falante ([3], 210) e tomar como regra geral que todos os seus proferimentos estão em relação estreita com suas crenças mais sinceras acerca do mundo. Na relação entre crenças e comportamento lingüístico, entre pensamento e linguagem, não é possível qualquer acesso privilegiado a um deles independente do outro, nenhum deles pode ser explicado completamente em termos do outro, não há nenhuma prioridade conceitual de um sobre o outro. A rigor, intenções, crenças, atitudes e palavras constituem uma unidade, e nenhuma parte pode ser destacada independentemente (Davidson defende uma teoria relacional da linguagem). Assim, nós não entendemos o que alguém quer dizer a menos que conheçamos suas crenças e nós não podemos conhecer suas crenças a menos que consigamos entender seus proferimentos.

A interpretação radical tenta romper esse círculo atribuindo um valor de crença verdadeira aos proferimentos ([I], 27). Para Davidson, crenças estão por sua própria natureza em estreita correlação com o tomar algo como verdadeiro ("belief is in its nature veridical", [3], 146). Com base nisso, a única forma de iniciar uma interpretação é tomar os proferimentos do falante como expressão de crenças, ou seja, como expressão daquilo que ele acredita ser verdadeiro:

A speaker who holds a sentence to be true on an occasion does so in part of what he means or would mean, by an utterance of that sentence, and in part because of what he believes. If all we have to go on is the fact of honest utterance, we cannot infer the belief without knowing the meaning, and have no chance of inferring the meaning without the belief ([1], 142)

O proferimento está associado a um contexto e essa correlação contextual servirá de evidência inicial para o intérprete: "we take the fact that speakers of a language hold a sentence to be true (under observed circumstances) as prima facie evidence that the sentence is true under those circumstances" ([1], 152). Somente pressupondo que o proferimento do falante em uma dada circunstância expressa uma crença que ele toma como verdadeira sobre o mundo, pode-se fixar um ponto de apoio inicial para o processo de interpretação: "We get a first approximation to a finished theory by assigning to sentences of a speaker conditions of truth that 
actually obtain (in our own opinion) just when the speaker holds those sentences true" ([1], 196). Nós interpretamos proferimentos conectando-os com as circunstâncias que se dão nas imediações do falante no momento de sua performance. Conhecer as circunstâncias nas quais o falante toma algo como verdadeiro é fundamental para a interpretação. Progredimos na interpretação quando procuramos estender essa adscrição inicial para o conjunto de crenças do falante e supomos que, em sua maioria, essas crenças são coerentes e verdadeiras.

Assim, a condição fundamental para uma interpretação radical bem sucedida é que o intérprete seja capaz de adscrever e identificar as pretensões de verdade implícitas nas enunciações do falante, associando-as às circunstâncias do mundo naquela ocasião. Para Davidson, uma teoria da verdade liga o falante ao intérprete, correlacionando os proferimentos com condições de verdade baseadas em evidências disponíveis publicamente. Identificar crenças implica, pois, a capacidade de ordená-las em relação aos objetos no mundo aos quais elas se referem.

\section{Interpretação e caridade}

A presunção de verdade por parte do intérprete em relação aos proferimentos do falante constitui o que Davidson denominou de Princípio de Caridade (principle of charity). O termo foi proposto por N. L. Wilson (1959) e usado largamente por Quine na idéia da tradução radical (Word and Object, cap. II). O princípio de caridade faz três exigências básicas: primeiro, que nós devemos pressupor que o falante não se encontra em erro; segundo, que seu sistema de crenças é coerente; e terceiro, que seu sistema de crenças não é tão diferente do sistema de crenças do intérprete, ou seja, de nosso sistema de crenças. Segundo Davidson:

Since charity is not an option, but a condition of having a workable theory, it is meaningless to suggest that we might fall into massive error by endorsing it... Charity is forced on us: wheter we like it or not, if we want to understand others, we must count them right in most matters ([1], 197).

A tese da verdade massiva do falante não implica que ele nunca erre ou tenha crenças falsas, mas somente que a maioria de suas crenças tem que ser tomada como verdadeira sob pena da interpretação falhar. Por outro lado, uma crença nunca pode ser avaliada sozinha, de forma isolada. Por conta do holismo do mental e do caráter inferencial das crenças, qualquer crença pertence a um conjunto estruturado de crenças e antes mesmo de poder julgar a verdade de uma crença específica é necessário já ter aceitado a verdade de muitas outras crenças. A possibilidade do erro não é negada, o que é negada é a possibilidade de sua generalização. Um falante pode afirmar a sentença "chove agora" e se enganar, quando no instante de seu proferimento não estiver chovendo em suas imediações, mas esse erro só pode ser registrado pelo intérprete se ele supuser que o falante tem alguma noção verdadeira acerca do que significa "chuva". Pressupor que o falante erra constantemente é, em termos davidsonianos, negar a possibilidade mesma de uma interpretação radical. Podemos, pois, excluir a possibilidade de um erro mas- 
sivo: em geral, quando o falante toma uma sentença como verdadeira, a sentença é verdadeira ([1], 168).

Sobre a exigência de que a interpretação proceda holisticamente, vale a pena destacar que não somente os proferimento e suas circunstâncias ocasionais contam como evidência para um intérprete, mas sobretudo a ligação sistemática das sentenças no interior de um sistema lingüístico. A interpretação se move, por isso, dentro de um horizonte de totalidade em que cada sentença é dependente de outras sentenças e deve ser consistente com elas. Em outros termos: existe uma presunção em favor da verdade daquela crença que seja coerente com a maior parte de crenças já assumidas. A consistência interna entre as sentenças é um princípio metodológico que guia o procedimento interpretativo de ponta a ponta ([1], 154). Esse princípio holístico confere à interpretação um caráter dinâmico, processual, circular e aberto a revisões. É possível, e mesmo necessário, ajustar permanentemente nossas interpretações a partir de novas evidências sobre as atitudes e crenças do falante, em um movimento que vai da sentença para o contexto - e vice-versa - e de uma crença para o conjunto de crenças, até atingirmos um equilíbrio na interpretação (vj. Ramberg, 78s; Malpas, 45s). O princípio holístico de interpretação tem seu fundamento na própria estrutura recursiva da linguagem, no caráter integral das atitudes e crenças das pessoas e na racionalidade de suas atitudes proposicionais (holismo psicológico):

"Words have no function save as they play a role in sentences: their semantic features are abstracted from the semantic features of sentences, just as the semantic features of sentences are abstracted from their part in helping people achieve certain goals and intentions" ([1], 220).

Davidson acredita que buscar explicitar sentido nos proferimentos e crenças dos outros implica em aumentar nosso grau de concordância com ele, de tal forma que sua fala somente ganha sentido através de nossa própria perspectiva. A concordância atuaria como um indicador do grau de validade da interpretação: o falante toma uma sentença como verdadeira em condições determinadas e tais condições se dão, na opinião do intérprete, exatamente quando o falante profere sua sentença ([1], 169). Por outro lado, o desacordo entre falante e intérprete é sinal de uma interpretação frustrada. O princípio de caridade adscreve, pois, aos outros crenças e desejos semelhantes aos nossos. Trata-se aqui de reconhecer, nas atitudes e proferimentos dos outros, padrões de racionalidade que não divergem muito dos nossos. Da mesma forma que a hermenêutica filosófica, a teoria da interpretação radical vai apontar para uma série de elementos contextuais e pressupostos necessários que constituem a condição de possibilidade da compreensão intersubjetiva:

The point is... that widespread agreement is the background against which disputes and mistakes can be interpreted. Making sense of the utterances and behaviour of others, even their most aberrant behaviour, requires us to find a great deal of reason and truth in them. To see too much unreason on the part of others is simply to undermine our ability to understand what it is they are so unreasonable about ([1], 153). 
O princípio de caridade funciona como uma espécie de princípio transcendental da interpretação, pois se queremos interpretar as expressões lingüísticas de um falante não podemos abrir mão dele (Davidson se refere a "argumento transcendental" em [1], 71). Ao interpretar, o intérprete não pode supor grandes desvios de seus próprios padrões de racionalidade sem destruir os fundamentos da inteligibilidade sobre os quais repousa toda interpretação. Caso contrário, teríamos que considerar a linguagem do outro como uma linguagem completamente incompreensível, uma linguagem privada, ou que seu comportamento não é de forma alguma lingüístico.

A "função transcendental" do princípio de caridade é reforçada pelas importantes consequiências sistemáticas que dele decorrem. A partir do princípio de caridade é possível: a) refutar o ceticismo e o falibilismo global; b) aceitar um grau de indeterminação entre interpretações rivais, sem que isso implique qualquer tipo de relativismo; c) defender uma teoria causal do significado e um sentido de objetividade compatível com uma epistemologia externalista; e d) mostrar a irredutibilidade do mental ao físico.

Sobre o primeiro ponto, Davidson procura mostrar que a tese do ceticismo e falibilismo global de que "todas as nossas crenças sobre o mundo externo poderiam ser falsas" pode ser descartada com base no princípio de caridade. Não é possível interpretar e atribuir falsidade à maior parte das crenças do falante ([3], 150). Se a interpretação atribui ao falante um comportamento que negue a maior parte dos fatos evidentes (segundo o ponto de vista do intérprete), então ela é uma péssima interpretação. Se há interpretação, tem que haver concordância em larga escala, falante e intérprete têm que partilhar de crenças comuns acerca do mundo: "No wonder, then, I can interpret your words correctly only by interpreting so as to put us largely in agreement" ([1], 200). Obviamente, cada uma de nossas crenças possa ser falsa isoladamente; é impossível, porém, que elas sejam todas falsas ao mesmo tempo. Esse argumento é reforçado pela teoria causal do significado, que veremos mais abaixo.

Quanto ao segundo ponto, o princípio de caridade é flexível o suficiente para permitir divergências entre interpretações, o que Davidson denomina de indeterminação da interpretação ([1], 240). Flexibilidade e indeterminação não significam, porém, que a interpretação é falha, mas somente que as diferenças nas interpretações não são significativas. Podemos obter várias teorias da interpretação, assim como temos vários sistemas de medição da temperatura ou de distâncias ([1], 154). Se existe indeterminação, é porque existem maneiras alternativas de situar os fatos que permaneceram em aberto. Diferentemente do que ocorre na tradução radical de Quine, o problema da indeterminação não é um problema central aqui.

Davidson aceita o pluralismo de "esquemas conceituais" ou de linguagens; o que ele nega é que eles sejam tão completamente diferentes uns dos outros que não pudessem permitir uma visão comum do mundo. O relativismo conceitual somente seria possível se: a) dado um esquema conceitual x qualquer - ou uma linguagem $\mathrm{x}$ qualquer, pudéssemos mostrar que $\mathrm{x}$ não é tradutível em nenhum outro esquema conceitual, ou em nenhuma linguagem diversa de $\mathrm{x}$; e b) fosse 
possível ter acesso a "esquemas conceituais" e linguagens independentemente de nosso próprio "esquema conceitual" ou linguagem, logo se fosse possível não interpretar o outro. Uma forma de atividade que não possa ser interpretada como uma linguagem em nossa linguagem não pode ser considerada uma forma de atividade lingüística. Que alguém fale uma linguagem totalmente incompreensível para nós é, nos cânones da interpretação radical, completamente impossível. Interpretabilidade e tradutibilidade são critérios de linguisticidade ([1], 185). Sobre o acesso independente a esquemas conceituais, ele afirma:

I reject conceptual relativism. Of course there are contrast from epoch to epoch, from culture to culture, and person to person, of kinds and struggle with; but these are wich with sympathy and effort we can explain and understand. Trouble comes when we try to embrace the idea that there might be more comprehensive diferences, for this seems (absurdly) to ask us to take up a stance outside our own ways of thought" ([3], 40).

"... there is no chance that someone can take up a vantage point for comparing conceptual schemes by temporarily shedding his own ([1], 185).

Assim, a metodologia da interpretação radical não nos permite considerar a maioria das crenças e opiniões dos outros como radicalmente diferentes de nossas próprias crenças e opiniões. Nós só podemos nos dar conta das diferenças à medida que nos tornamos também conscientes do solo comum de crenças partilhadas ([1], 200).

Como conseqüência da aceitação do princípio de caridade, decorre a postulação de uma teoria causal (externalista) da significação, segundo a qual "não há nada mais a ser conhecido sobre a relação entre crenças e o resto da realidade do que o que aprendemos a partir de um estudo empírico das transações causais entre organismos e seus ambientes" (Rorty, 341). O externalismo acredita na relação causal entre nossas crenças e as circunstâncias que nos envolvem; no caso de Davidson, essa relação assume um papel meramente evidencial para a interpretação das reações e proferimentos do falante ([8], 10s.). A diferença básica em relação à teoria causal de referência de S. Kripke (1972) e H. Putnam (1975) é que, para Davidson, essa relação não é corpuscular, atômica entre nomes e objetos, mas sim holística entre conjunto de crenças e história do universo. Para a teoria causal da referência, qualquer descrição de um objeto poderia ser falsa e mesmo assim o objeto referido permaneceria o mesmo. Segundo ele, a teoria causal de Kripke e Putnam abre a possibilidade para que objetos referentes e objetos intencionais não tenham nada a ver uns com os outros, e nesse sentido, não estão ao abrigo do tipo de cesura comum nos parâmetros do dualismo esquema conceitualconteúdo:

What stands in the way of global skepticism of the senses is, in my view, the fact that we must, in the plainest and metodologically most basic cases, take the objects of a belief to be the causes of that belief [...] Communication begins where causes converge: your utterance means what mine does if belief in its truth is systematically cause by the same events and objects ([3], 151). 
Mesmo advogando uma teoria causal do significado, Davidson não acredita que isso implique o retorno a uma teoria da referência nos moldes tradicionais, ou seja, uma teoria da referência que parte ainda da separação entre esquema conceitual e mundo, comprometida com uma semântica atomista.

\section{Racionalidade universal e objetividade intersubjetiva}

Em um artigo de 1991, Tree Varieties of Knowledge, Davidson se refere a dois princípios adicionais que podem figurar como formas do princípio de caridade: o princípio da coerência e o princípio da correspondência ([3], 211). O princípio da coerência possibilita ao intérprete descobrir um elevado nível de consistência lógica naquilo que o falante pensa. O princípio da correspondência, por outro lado, permite ao intérprete partir da suposição de que o falante está respondendo aos mesmos aspectos do mundo que ele, intérprete, responderia em condições semelhantes. O primeiro princípio se refere a padrões de racionalidade consubstanciados na lógica; o segundo se refere à objetividade das crenças. Para Davidson, decorre da natureza da interpretação que se possa postular um padrão intersubjetivo de consistência e um tipo de "correspondência" objetiva a um mundo comumente partilhado entre falante e intérprete. Dessa forma, o princípio de caridade implica o reconhecimento de uma racionalidade intersubjetiva e da partilha de um mundo comum, que pode ser designado de mundo objetivo ("the very possibility of thought demands shared standards of truth and objectivity" [3], 52). A explicitação dessa racionalidade intersubjetiva mínima e, sobretudo, daquilo que Davidson entende por objetividade, vai ser feita através da idéia de "triangulação", que ganhou lugar predominante em seus textos da década de 90.

The basic situation is one that involves two or more creatures simultaneously in interaction with each other and with the world they share; it is what I call triangulation. It is the result of a threefold interaction, an interaction which twofold from the point of view of each of the two agents: each is interacting simultaneously with the world and with the other agent... each creature learns to correlate the reactions of other creatures with changes or objects in the world to which it also reacts ([3], 128).

O conceito de triangulação tenta dar conta da relação dinâmica entre intérprete (primeira pessoa), falante (segunda pessoa) e mundo. A triangulação é a fonte da comunicação e da objetividade intersubjetivas, bem como dos processos de individuação subjetivos. Trata-se de uma espécie de situação originária em que pensamento, linguagem e mundo - ou primeira pessoa, segunda pessoa e realidade - surgem simultaneamente. Davidson, aceita a tese de Wittgenstein da impossibilidade de uma linguagem privada e considera que linguagem e pensamento são essencialmente sociais. Linguagem e pensamento pressupõem que pelo menos um indivíduo interage com outro indivíduo em um mundo comum: "a creature must be a member of a speech community if it is to have the concept of belief... only a creature that can interpret speech can have the concept of thought" ([1], 170). Davidson defende uma teoria relacional em que não há prioridade do pensamento sobre a linguagem, nem da linguagem sobre o pensamento: eles são 
co-originários e co-dependentes. Para ele, o critério distintivo entre seres humanos e os outros animais é que seres humanos são capazes de atitudes proposicionais: "to have propositional attitudes is to be a rational creature" ([3], 99). Um indivíduo não pode ser capaz de fala e ser irracional. Racionalidade é um traço social e somente pessoas que se comunicam a possuem ([3], 105).

Racionalidade é tomada aqui em sentido holístico: não é uma crença ou atitude isolada que pode ser determinada como racional ou não, mas a interconexão das crenças entre si e com as atitudes de uma pessoa. Ter uma crença já implica ter muitas crenças; elas dão suporte e conteúdo umas às outras e estão em íntima conexão lógica entre si. Neste contexto, o princípio de não-contradição e as constantes lógicas que garantem a interconectividade das crenças, ações e proferimentos desempenham um papel fundamental: a incoerência radical é impossível ([3], 99). Não se trata aqui de uma escolha arbitrária individual, mas de princípios constitutivos de todo ser que é capaz de ter atitude proposicional ou que age intencionalmente: "Rationality, in this primitive sense, is a condition of having thoughts at all" ([4, 196]).

A tese de que o princípio de caridade exige a adscrição de racionalidade se mostra pelo fato de que compreender os proferimentos e ações de um outro indivíduo só é possível à base de um padrão de racionalidade comum partilhado por todas as criaturas racionais. Davidson estende assim o requisito metodológico de adscrição de racionalidade do princípio de caridade para toda a humanidade enquanto tal; aquilo que vale para a situação de interpretação entre dois indivíduos, vale para a totalidade de indivíduos ([6], 320). Um argumento para essa ampliação é a transitividade da relação de interpretação: se A pode interpretar B e B pode interpretar C, então A pode interpretar C. Por outro lado: se A pode interpretar B e A pode interpretar $\mathrm{C}$, então $\mathrm{B}$ e $\mathrm{C}$ não têm padrões de racionalidade e objetividade tão diferentes. Nesse sentido, o princípio de caridade é a expressão metodológica da pressuposição de uma comunidade de falantes que inclui toda a humanidade (cf. Malpas, 96s.).

A prova de objetividade - que intérprete e falante tenham acesso a um mundo comum - decorre dos pressupostos do projeto interpretativo e do caráter transcendental do princípio de caridade. "To understand the speech of another, I must be able to think of the same things she does; I must share her world (...) But the concept of an intersubjective world is the concept of an objective world" $[3,105]$. Para Davidson, em primeiro lugar, nós somos dotados de uma noção de verdade que implica poder fazer a distinção entre o verdadeiro e o falso, o real e o aparente. Segundo, a idéia de algo externo, independente de nós, emerge da situação de triangulação. A objetividade resulta da interação social entre duas pessoas em uma situação qualquer. Da correlação que cada um faz da reação do outro às circunstâncias externas comuns surge o conceito de objetividade ([3], 202). Para Davidson, a objetividade resulta da impossibilidade de pensar a realidade como inacessível a nós, pois tal noção implicaria que a linguagem poderia ser constituída independentemente das relações causais com o ambiente: "Objectivity itself we have traced to the intersections of point of views - for each person, the relati- 
on between his own reaction to the world and the reactions of others" ([3], 218). Não teríamos acesso às atitudes proposicionais dos outros sem interpretar seu comportamento lingüístico e não interpretamos sua linguagem sem efetuar a correlação com a configuração do mundo no momento do proferimento. O que vincula linguagem e mundo de modo necessário é que, em última instância, as condições que nos levam a sustentar nossas crenças e proferimentos constituem ao mesmo tempo as condições de verdade e significado dessas sentenças. Assim, o mundo é tanto mediador entre as mentes, quanto a comunidade de mentes é a base de toda idéia de mundo objetivo: "Intersubjectivity is the root of objectivity, not because what people agree on is necessarily true, but because intersubjectivity depends on interaction with the world" ([3], 91). Como afirma Davidson, o solipsista não tem mundo ([3], 119; [8], 13).

$\mathrm{Na}$ teoria davidsoniana, é possível falar de verdade e objetividade sem falar em referência ou correspondência com os fatos. Esta tese vai ser expressa como o slogan: correspondência sem confrontação. O conceito de verdade objetiva é condição de possibilidade de interpretação de sentenças: "without a grasp of the concept of truth, not only language, but thougth itself, is impossible" ([7], 72). Por outro lado, a verdade não é uma meta, algo a ser atingido. Verdade já está desde sempre presente em nossos proferimentos como condição de sua inteligibilidade.

A verdadeira objeção às teorias da correspondência não é a afirmação de que elas remetem a verdade a uma instância que seres humanos não podem aspirar, mas sim que fracassam em determinar as entidades à quais as sentenças, proferimentos, asserções deveriam corresponder. Por isso, a idéia de uma confrontação de sentenças com pedaços quaisquer de itens extralingüísticos é absurda. Nada pode tornar uma sentença verdadeira, a não ser sua relação dentro de um todo coerente de crenças: "I suggeste we give up the idea that meaning or knowledge is grounded on something that counts as an ultimate evidence" ([3], 146); "Nothing, no thing, makes our statements true" ([3], 184). A noção de evidência nãoepistêmica é substituída por uma noção doxástica integralmente holística em que: a) somente uma crença pode servir de justificação para outra crença; b) a verdade de uma crença é uma função do seu grau de coerência e compatibilidade dentro de um sistema de crenças.

A "epistemologia" davidsoniana se contrapõe ao fundacionalismo e se coloca completamente ao lado do inferencialismo. Mas nem por isso sua posição coerentista epistêmica implica algum modo de anti-realismo(Evnine, 155ss.). Para Davidson, é possível ser objetivista sem ser realista metafísico e é possível defender que não existe nada - nem fatos, nem experiência, nem mundo - que torne sentenças verdadeiras sem ser internalista ([3], 140s; [6], 309s.). Ele pretende ver sua posição descrita como um tipo de externalismo, em que objetos e eventos externos relevantes para o falante e para o intérprete são causadores das crenças: "Communication begins where causes converge: your utterance means what mine does if belief in its truth is systematically caused by the same events and objects" ([3, 151]). 


\section{Interpretação radical versus hermenêutica filosófica}

No começo desse artigo, afirmamos que Davidson promoveu uma virada hermenêutica dentro da semântica formal e compreendeu que uma teoria do significado só é possível à base de uma teoria da verdade e da interpretação. Chegou a hora de por à prova nossa hipótese inicial da convergência do projeto davidsoniano com a hermenêutica filosófica.

Primeiramente, não há como negar que o procedimento holístico da interpretação radical aparenta uma semelhança quase univitelina com a idéia gadameriana do círculo hermenêutico. Como Davidson, Gadamer também defende que a antecipação do todo é fundamental para entender as partes. Além disso, o procedimento hermenêutico é guiado de ponta a ponta por uma expectativa de sentido (Sinnerwartung) e por uma antecipação de sentido (Antizipation von Sinn). Como afirma Gadamer: "Einstimmung aller Einzelheiten zum Ganzen ist das jeweilige Kriterium für die Richtigkeit des Verstehens. Das Ausbleiben solcher Einstimmung bedeutet Scheitern des Verstehens" ([2], 57). Do círculo hermenêutico é possível concluir que somente pode ser compreendido aquilo que tem uma unidade de sentido, a isso Gadamer denomina "Vorgriff der Vollkommenheit" ([1], 299), que é o correspondente hermenêutico do princípio de caridade davidsoniano.

Apesar dessa semelhança de fundo, há, no entanto, diferenças significativas entre a metodologia da interpretação radical e o procedimento da hermenêutica filosófica. Antes de mais nada, no centro da hermenêutica gadameriana está a idéia de diálogo entre dois falantes como processo de aproximação através do mecanismo de pergunta e resposta. Para Davidson, ao contrário, o processo de interpretação não implica diálogo, ele não requer nem mesmo uma linguagem comum:

Perhaps it is worth pointing out that the notion of a language, or of two people speaking the same language does not seem to be needed her. Two speakers could interpret each other's utterances without there being, in any ordinary sense, a common language ([1], 157).

As convenções lingüísticas não podem ser meio da interpretação, pois elas pressupõem já a interpretação. Dessas considerações, Davidson extrai a tese, no mínimo inaudita, da inexistência da linguagem:

I conclude that there is no such thing as a language, not if a language is anything like what many philosophers and linguists have supposed. There is therefore no such thing to be learned, mastered or born with. We must give up the idea of a clearly defined structure which language-users acquire and then apply to cases. And we should try again to say how convention in any important sense is involved in language; or as I think, we should give up the attempt to illuminate how we communicate by appeal to conventions ([4], 446).

Essa tese foi considerada absurda por Hacking ([2], 447) e Dummet ([2], 465s.) que viram nela uma espécie de nihilismo lingüístico, inconsistente com a tentativa de explicitar o significado de uma sentença em L. Por razões metodológicas, justi- 
fica-se que Davidson conceda aqui primazia à "parole" e não à "langue", para usar a célebre distinção de Saussure, e que ele tome como ponto de partida da interpretação sempre o idioleto e não o socioleto. A linguagem convencional é somente uma abstração e não há nada filosoficamente relevante com essa abstração. Uma das vantagens dessa posição extremada é que ela exorciza definitivamente os fantasmas da reificação, como bem frisou Ramberg (2).

No entanto, de que forma é possível comunicação sem linguagem convencional é algo que Davidson não esclarece bem. Ele parece sugerir que existe uma instância normativa implícita nas atitudes proposicionais dos indivíduos em situação de triangulação. Se, aquilo que falante e intérprete compartilham não pode ser aprendido e não pode ser fixado em um sistema de regras ou convenções, eles precisam adaptar suas teorias de interpretação a cada instante, de acordo com as evidências fornecidas pela observação do comportamento do outro ([4], 445). A insistência davidsoniana na importância da interação causal entre falante e mundo alimenta a suspeita de uma assimilação do "paradigma da compreensão" ao "paradigma da explicação", no âmbito do qual ao invés de interagir lingüisticamente, o intérprete é um observador externo que constata e busca explicar o comportamento lingüístico dos indivíduos.

Nessa eliminação da linguagem no processo de interpretação, McDowell (184s.) vê uma diferença radical com a hermenêutica. Segundo ele, partilhar uma linguagem comum, como repositório de tradições, é o medium primário do entendimento entre indivíduos. O modelo davidsoniano da comunicação parte, entretanto, de indivíduos autônomos, cada um possuindo um idioleto particular e pressupondo a convergência de idioletos. Essa convergência se dá pela assunção de estruturas de racionalidade comuns (a qual McDowell, diga-se de passagem, é simpático), explicitadas somente como exigência metodológica da interpretação. Uma justificação independente dos pressupostos metodológicos inexiste em Davidson. O intérprete davidsoniano apenas toma a opção tática e estratégica de interpretar o comportamento do outro como intencional, podendo abandonar essa hipótese caso ela se mostre infrutífera metodologicamente. Há aqui uma similaridade com Dennet $(1978,6)$ para quem a atribuição de atitudes proposicionais para explicação do comportamento de sistemas complexos é uma aposta que esperamos que valha a pena.

Na mesma direção, Demmerling (61ss.) procura mostrar que Davidson ainda permanece preso ao ideal das ciências da natureza de uma teoria explanatória dedutivo-nomológica, que pretende explicar o uso de expressões lingüísticas a partir de testes empíricos. O conceito formal de teoria, sua pretensão explanatória objetivista e a exigência de testabilidade empírica são características que mostram, segundo Demmerling, o quanto o conceito de interpretação de Davidson está ligada a uma tradição de filosofia da linguagem cienticista que não consegue "emancipar a gramática da lógica", como queria Heidegger. Ainda na mesma linha de argumentação, Mulhall $(1987,322)$ faz uma interpretação behaviorista de Davidson e caracteriza o universo davidsoniano como completamente vazio de 
significação, no qual a experiência da humanidade de outras pessoas é "um constructo teórico a partir de um fato bruto".

Também Habermas acredita que Davidson objetificou o fenômeno da interpretação, na medida em que tornou o intérprete um teórico experimental que faz considerações sobre culturas diferentes a partir de observações empíricas. Do ponto de vista do intérprete-teórico, a interação simbólica e a comunicação são tratados objetivamente como meros fenômenos da natureza. Para Habermas, o emprego do conceito de racionalidade em Davidson para explicar a ação dos indivíduos tem função meramente descritiva, que não pode ser confundida com sua função normativa em contextos de comunicação. Segundo ele, apesar da triangulação entre subjetividade, intersubjetividade e objetividade, Davidson não escapa ao solipsismo metodológico, pois o indivíduo na ponta do triângulo não pode se comunicar com o outro para estabelecer se as respostas aos estímulos externos são realmente respostas aos mesmos estímulos: "Die Wahl eines objektivistischen Ansatzes, der Sinnverstehen an theoriegeleitetes Erklären assimiliert, bedeutet die Entscheidung für einen methodischen Solipsismus" (67). Por essas razões, Habermas vê a hermenêutica filosófica, a rigor, como uma contraposição às tendências objetivadoras da interpretação radical.

Por fim, uma última consideração. Os hermeneutas geralmente costumam se referir à hermenêutica filosófica não como uma metodologia da interpretação, mas antes como uma espécie de ontologia que envolve sempre uma pré-compreensão do ser e do ser-com. Advindo de uma tradição que teve como questão fundamental a questão do significado das palavras e sentenças, a solução davidsoniana mostra que tal investigação só é possível quando conseguimos dar conta de suas ações e atitudes. O objetivo de Davidson não é a decodificação de expressões, mas fornecer um sentido total da forma de viver e pensar do falante (Wiggins, 18). A interpretação é somente um elemento em uma tentativa mais ampla de compreender seres humanos enquanto animais racionais que interagem e coordenam lingüisticamente suas ações.

\section{Referências}

DAVIDSON, D. [1]: Inquiries into Truth and Interpretation. Oxford: Clarendon Press, $1984^{1}, 2001^{2}$.

_ . [2]: Essays on Actions and Events. Oxford: Clarendon Press, $1980^{1}, 2001^{2}$.

_. [3]: Subjective, Intersubjective, Objective. Oxford: Clarendon Press, 2001.

- [4]: Problems of Rationality, Oxford: Clarendon Press, 2004.

_. [5]: "A Nice Derangement of Epitaphs". In: E. LePORE (ed.), p. 433-446.

_. [6]: "The Structure and Content of Truth". In: Journal of Philosophy, 87 (1990), p. 279-328.

. [7]: "Truth Rehabilited". In: R. BRANDOM (ed.), Rorty and his Critics. Oxford: Basil Blackwell, 2000, p.65-73.

_. [8]: Der Mythos des Subjektiven. Philosophische Essays. Stuttgart: Re-clam Verlag, 1993. 
DEMMERLING, C.: Sinn, Bedeutung, Verstehen. Untersuchungen zu Sprachphilosophie und Hermeneutik. Paderborn: Mentis Verlag, 2002.

DENNET, D. "Intensional Systems". In: do mesmo, Brainstorms: Philosophical Essays on Mind and Psichology. Montgomery: Bradford Books, p. 3-22, 1978.

DUMMET, M [1].: "What Is a Theory of Meaning? (I)". In: S. GUTTENPLAN (ed.), Mind and Language. Oxford: Oxford University Press, 1975, p. 97-138.

[2]: "A Nice Derangement of Epitaphs: Some Comments on Davidson and Hacking". In: In: E. LePORE (ed.), p. 459-476.

EVNINE, S.: Donald Davidson. Stanford: Stanford University Press, 1991.

FOSTER, J.: "Meaning and Truth Theory". In: G. EVANS/J. McDOWELL, J. (ed.), Truth and Meaning: Essays in Semantics. Oxford: Oxford University Press, 1976, p. 1-32.

GADAMER, H.-G. [1]: Wahrheit und Methode. In: Gesammelte Werke, Bd. I. Tübingen: J.C.B. Mohr, $1960^{1}, 1990$. 1990, p. 57-65.

HABERMAS, J.: Kommunikatives Handeln und detranszendentalisierte Vernunft. Stuttgart: Reclam Verlag, 2001.

HACKING, I. [1]: Why Does Language Matter to Philosophy? Cambridge: Cambridge University Press, 1975.

. [2]: "The Parody of Conversation". In: In: E. LePORE (ed.), p. 447-458.

HAHN, L. E. (ed.): The Philosophy of Donald Davidson. Chicago and LaSalle, Illinois: Open Court, 1999

KRIPKE, S.: Naming und Necessity, Cambridge (Mass.): MIT Press, 1972.

LePORE, E.: Truth and Interpretation: Perspectives on the Philosophy of Donald Davidson. Oxford: Basil Blackwell, 1985.

LUDWIG, K.(ed.): Donald Davidson. Cambridge: Cambridge University Press, 2003.

MALPAS, J. E.: Donald Davidson and the Mirror of Meaning. Holism, Truth, Interpretation. Cambridge: Cambridge University Press, 1992.

McGINN, C.: "Radical Interpretation and Epistemology". In: E. LePORE (ed.), p. 358-368.

McDOWELL, J.: Mind and World. Cambridge: Cambridge University Press: 1994.

MULHALL, S.: "Davidson on Interpretation and Understanding", In: Philosophical Quarterly, 37, p. 319322

PUTNAM, H.: "The meaning of meaning", in: Mind, Language, Reality. Philosophical Papers, v. 2, Cambridge: Cambridge University Press, 1983, p. 215-271.

QUINE, W.V.O.: Word and Object. Cambridge (Mass.): MIT Press, $1960^{1}, 1983^{13}$.

RAMBERG, B.: Donald Davidson's Philosophy of Language: An Introduction. Oxford: Basil Blackwell, 1989.

RORTY, R.: "Pragmatism, Davidson and Truth". In: E. LePORE (ed.), p. 333-354.

WIGGINS, D.: "Meaning and Truth Conditions: From Frege's Grand Design to Davidson's". In: HALE, B./WRIGHT, C., A Companion to the Philosophy of Language. Oxford: Blackwell, 1997, p. 3-27 